\title{
Makna Lirik Lagu Gawi "Ine Pare" Karya Frans Tuku (Analisis Semiotik Carles S. Peirce)
}

\author{
Idris Mboka, Ilham Syah \\ Program Studi Pendidikan Bahasa Dan Sastra Indonesia \\ Universitas Muhammadiyah Kupang \\ idris.mboka@yahoo.com
}

\begin{abstract}
Abstrak: Penelitian ini bertujuan untuk mendeskripsikan representasi makna tanda ikon, indeks, dan simbol pada lirik lagu Gawi "Ine Pare" karya Frans Tuku. Teori yang digunakan dalam penelitian ini adalah teori semiotik Carles S. Pierce dengan menggunakan metode deskripsi kualitatif. Berdasarkan hasil analisis data ditemukan tanda berupa ikon, indeks dan simbol. Representasi makna ikon Gawi pada lirik lagu Gawi "ine pare” karya Frans Tuku adalah momentum mempererat hubungan tali persaudaraan antara sesama dan ungkapan rasa syukur kepada sang pencipta dan leluhur. Representasi makna Ikon nggua pada lirik lagu Gawi "Ine Pare" karya Frans Tuku adalah pesta adat penyambutan musim tanam yang diselenggarakan pada saat memasuki musim penghujan. Indeks ruang bermakna penunjukkan ruang atau arah tempat. Representasi makna indeks yaitu; berkaitan dengan tempat-tempat dilakukanya ritual adat nggua. Representasi makna indeks temporal yakni; pelaksanaan ritual adat nggua yang dilakukan merupakan amanat leluhur yang harus di jaga dan dijalankan sehingga masyarakat terselamatkan dari mara bahaya atau bencana. Representasi makna indeks personal; orang-orang yang terlibat pada saat ritual maupun pada saat melakukan tarian Gawi. Representasi makna simbol pada lirik lagu Gawi "Ine Pare” karya Frans Tuku secara umum merepresentasikan realitas sosial-budaya masyarakat etnik Lio. Mosalaki memegang peranan penting dalam adat istiadat yang diwarisi leluhur diantaranya masalah sosial-budaya, ekonomi dan lain sebagainya. Selain itu, makna simbol pada lirik lagu Gawi "ine Pare” karya Frans Tuku merepresentasikan masalah-masalah sosial yang terjadi seperti perbuatan yang melanggar norma adat istiadat seperti kecurangan dalam mencari nafkah, perkawinan dini serta perkawinan sedarah.
\end{abstract}

Kata Kunci: lirik lagu gawi, semiotik, tanda, makna, representasi

Absctract: This study aimed at describing the representation of icon, index and symbol in the Gawi's song lyrics "Ine Pare" by Frans Tuku. Carles S. Pierce's semiotic theory is used on this study with descriptive qualitative research design. The study showed that the was icons, indexes and symbols in "Ine Pare" song lyrics. The representation of icon in the song was strengthen fraternity and expressing gratitude to the God and the ancestors. The representation of nggua icon in the "Ine Pare" song lyrics was traditional party to welcome the planting season which is held in the early of the rainy season. Index of space meant the designation of space or direction of a place. Representation of index was related to the place where Nggua ritual is performed. Representation of temporal index was the Nggua traditional ritual is the ancestor mandate that 
should be preserved and carried out so that the community is saved from any kind of disasters. Representation of personal index; those who involved during the ritual or those who performing the Gawi dance. Generally, the representation of symbolic meaning in Gawi's song lyrics "Ine Pare" by Frans Tuku represented the socio-cultural reality of the ethnic Lio community. Mosalaki was an important role in the inherited customs from ancestors including socio-cultural, economic and so on. In addition, the symbol meaning on the Gawi's song lyrics "Ine Pare" by Frans Tuku represented the social problems such as violating the norms of custom: deceit in life, early age marriage and incest of marriage.

Keywords: Gawi Song Lyrics, Semiotic, Sign, Meaning, Representation.

\section{Pendahuluan}

Salah satu tarian tradisional di Kabupaten Ende adalah tarian gawi "tandak". Tarian Gawi merupakan tarian tradisonal yang melibatkan banyak orang baik perempuan maupun laki-laki dengan cara bergandengan tangan dan mementuk lingkaran sambil menghentakan kaki. Tarian ini dilakukan ketika upacara adat penyambutan musim tanam nggua dan acara-acara seremonial biasa seperti perkawinan dan sambut baru. Tarian gawi diiringi dengan musik atau lagu yang disebut dengan lagu Gawi. Lagu Gawi biasanya dinyanyikan oleh satu orang atau lebih dengan menggunakan bahasa-bahasa simbolik yang menggambarkan realitas kehidupan masyarakat etnik Lio.

Penggunaan bentuk metaforis mendominasi dari awal hingga akhir lirik lagu. Selain itu, dalam lagu Gawi menampilkan nada dan ritme yang khas serta durasi waktu yang panjang. Bentuk-bentuk bahasa yang digunakan pada lirik lagu Gawi tidak terlepas dari konteks sosiobudaya masyarakat guyub tutur etnik Lio. Lirik lagu merupakan ungkapan atau perasaan berdasar pengalaman, cerita, atau penglihatan yang dituangkan menjadi sebuah seni.

Lagu sebagai sarana hiburan memiliki pesan yang disampaikan pencipta lagu kepada pendengarnya. Ekspresi linguistik yang digunakan dalam lirik lagu Gawi merupakan salah satu media pengungkapan makna. Makna adalah kerangka konseptual yang menggambarkan kategorisasi dalam dunia dengan melihat makna sebagai gambaran berkas mental para penuturnya. Dengan kata lain, makna merupakan isi atau pokok dari sebuah bahasa penuturnya. Makna tidak terpisah dengan bahasa itu sendiri dengan adanya makna manusia dapat memahami satu sama lain.

Penelitian ini menggunakan teori semiotik sebagai pisau analisis guna mengungkapkan makna yang terkandung dalam lirik lagu Gawi "Ine Pare" karya Frans Tuku. Menurut Hoed (2011:3) semiotik adalah ilmu yang mengkaji tanda dalam kehidupan manusia. Artinya, semua yang hadir dalam kehidupan kita dilihat sebagai tanda yakni sesuatu yang harus diberi makna]. Selaras dengan pandangan tersebut Pierce (dalam Danesi, 2004:33) mengungkapkan bahwa "Kehidupan intelektual dan sosial manusia didasarkan pada penghasilan, penggunaan, dan pertukaran tanda. Saat kita membuat isyarat, berbicara, menulis membaca, menonton acara TV mendengar musik, melihat lukisan, kita tengah melakukan penggunaan dan penafsiran tanda." Pernyataan tersebut menyiratkan bahwa seluruh aspek kehidupan manusia menggunakan tanda sebagai medium untuk berkomunikasi. 
Masalah yang di angkat dalam penelitian ini yakni; bagaimana represetasi makna tanda ikon, indeks, dan simbol yang terkandung dalam lirik lagu Gawi "Ine Pare” karya Frans Tuku. Adapun tujuan dari peneltian ini yaitu; untuk mendeskripsikan representasi makna tanda ikon indeks dan simbol pada lirik lagu Gawi "ine pare” karya Frans Tuku.

\section{Metode Penelitian}

Teori semiotik merupakan teori interpretasi. Teori ini fokus pada pengkajian tanda, baik tanda verbal maupun tanda non verbal, sehingga metode penelitian yang dianggap paling relaevan dalam melakukan penelitian ini adalah metode deskriptif kualitatif. Menurut Sukmadinata (2011: 73) penelitian deskriptif kualitatif ditujukan untuk mendeskripsikan dan menggambarkan fenomena yang ada, baik bersifat alamiah maupun rekayasa manusia, yang lebih memperhatikan karakteristik, kualitas, dan keterkaitan antar kegiatan. Pandangan tersebut menyiratkan bahwa penelitian deskriptif kualitatif adalah kegiatan menginterpretasi atau menggambarkan suatu objek penelitian dengan cara deskripsi sehingga bermakna.

\subsection{Metode Pengumpulan Data}

Ada empat macam teknik pengumpulan data yaitu, observasi, wawancara, dokumentasi dan tringulasi. Penelitian ini merupakan penelitian kepustakan, namun dalam mencari makna suatu tuturan peneliti dituntut untuk mengetahui konteks di mana tuturan itu berlangsung atau dalam hal ini konteks ketika lagu Gawi digunakan sehingga keterlibatan peneliti di lapangan diharuskan untuk mencari tahu makna yang terkandung dalam lirik lagu tersebut. Sumber data dalam penelitian ini adalah; (1) Teks lagu gawi. Teks lagu yang akan diteliti oleh penulis adalah lagu Gawi "Ine Pare" yang diciptakan oleh Frans Tuku.

\subsection{Teknik Pengolahan Data}

Berpegang pada sumber data penelitian ini, maka data dapat dianalisis dengan menggunakan beberapa teknik; (1) transkrip Data; (2) Pengaksaraan; (3) penerjemahan; (4) pengelompokan data; (5) interprestasi

\section{Hasil dan Pembahasan}

Untuk menafsirkan tanda-tanda yang terdapat dalam lirik lagu gawi karya Frans Tuku diperlukan pemaknaan. Pemaknaan adalah upaya mengonstruksikan bentuk atau tanda dengan mengkaitkan konteks budaya tertentu. Tanda yang akan dibahas pada sub-bab ini adalah ikon, indeks dan simbol.

\subsection{Ikon}

Ikon adalah tanda yang memiliki kemiripan dengan objeknya. Menurut (Danesi, 2004: 38-39) “... ikon adalah sebuah tanda yang ada, dibuat agar mirip dengan sumber acuannya secara visual". Pada teks lirik lagu Gawi "Ine Pare" karya Frans Tuku ikon yang pertama adalah gawi seperti terdapat pada data (1-2)

1. o...le..le...lea $3 x$ mai gawi de gha sena....

o...le..le...lea $3 \mathrm{x}$ mari gawi kesini segera 
'hai-hai marilah segera kita menari tandak'

Teks pada data (1) di atas merupakan bentuk ajakan untuk menari Gawi 'tandak'. Kata Gawi secara harafiah bermakna 'mengayunkan tangan'. Tarian Gawi merupakan salah satu ikon masyarakat etnik Lio, Tarian Gawi dipentaskan pada acara adat, pesta dan hajatan lainya. Dalam konteks lirik lagu gawi karya Frans Tuku, tarian Gawi dilakukan pada saat ritual adat yang berlokasi di lodo nda 'lapangan'. Representasi makna ikon Gawi pada lirik lagu Gawi “ine pare' karya Frans Tuku adalah momentum mempererat hubungan tali persaudaraan antara sesama dan ungkapan rasa syukur kepada sang pencipta dan leluhur.

2. laki tau nggua kiwa iwa duna le.....le... ketua adat buat ritual adat tahun tidak kurang le......le...

'Setiap tahunya ketua adat melangsungkan ritual adat penyembutan musim tanam ya...ya...'

Teks pada data (2) ikon ditunjukkan dengan kata nggua. Secara harafiah kata nggua memiliki makna 'sekumpulan orang'. Nggua merupakan istilah untuk menyebutkan acara seremonial adat penyambutan musimtanam yang diadakan setiap tahunya. Nggua merepresentasikan masyarakat etnik Lio yang religius yang pada momen itu bersama-sama dengan ketua adat melakukan ritual untuk memohon perlindungan serta memohon rezeki dari dua nggae 'Tuhan yang maha kuasa' dan dua bapu atamata 'para leluhur'.

\subsection{Indeks}

Indeks adalah tanda yang mempunyai keterkaitan fenomenal atau peristiwa ekstensial. Danesi, (2010: 38) membagi tanda indeks menjadi tiga jenis yaitu; indeks ruang, indeks temporal, indeks persona.

\subsubsection{Indeks Ruang}

Indeks ruang mengacu pada lokasi atau ruang suatu benda, mahluk dan peristiwa dalam hubungannya dengan pengguna tanda. Contoh indeks ruang adalah anak panah yang menunjukan arah tertentu dan biasa diartikan dengan kata penjelas yang menunjukan sesuatu, seperti di sana, di situ. (Danesi,2004: 43). Dalam berkomunikasi, kata penjelas memiliki peran yang sangat penting seperti untuk menjelaskan keberadaan atau arah suatu objek dalam kaitannya dengan konteks tertentu. Dalam kaitannya dengan lirik lagu Gawi "Ine Pare" karya Frans Tuku, terdapat beberapa indeks ruang seperti pada kutipan data 3-11 di bawah ini.

\section{4 kali mema au ghale tubu kanga}

gali memang aur disana potongan batu

menancapkan bambu aur pada arena

Teks pada data (3) indeks arah berupa kata ghale 'timur' dalam konteks lirik lagu Gawi karya Frans Tuku arah tersebut menunjukkan lodo nda 'tempat ritual' dan juga sebagai tempat menari. Representasikan Makna Indeks ghale "timur" merupakan tempat ritual. Pada tempat 
tersebut digali lubang untuk menancapkan bambu aur. Bambu aur yang akan di tancapkan dilengkapi dengan nyiru yang diikat pada ujung atas bambu. Bambu aur dan nyiru diyakini sebagai tameng untuk menangkis ancaman dari jin/setan.

\section{5 boka kuku mbaku welu ghele watu} jatuh kaki sayap taroh atas batu sesajian yang telah ditaruh di bagian selatan

Teks pada data (4) indeks arah berupa kata ghele 'atas' kata ghele dapat bermakna ganda jika konteksnya berbeda. Pada konteks lirik lagu gawi karya Frans Tuku, kata ghele diartikan sebagai, bagian atas atau di atas. Makna penunjukan arah ghele mereprentasikan geografi wilayah perbukitan pada tempat ritual tersebut. Gunung dan perbukitan merupakan tempat yang tinggi sehingga dalam penyebutan untuk menunjukkan arah ke gunung disebut ghele keli 'di atas gunung' atau ghele wolo 'di atas bukit.

6 nitu nira napa ghawa lele dagha

jin lihat tunggu disana beringin miring

'setan telah menunggu di pohon beringin'

Teks pada data (50 di atas, indeks arah berupa kata ghawa 'barat', menunjukan bagian barat perkampungan dimana pada bagian tersebut terdapat pepohonan beringin serta batu batuan yang besar. Di tempat tersebut telah dilakukan ritual dengan memberikan sesajian yang diletakan di bawah pohon dan di atas batu. Batu dan pohon beringin diyakini oleh masyarakat etnik Lio memiliki penghuni.

\section{7 jejo lau eko ma'e sembho gebo}

mengarak utara jangan sembarang ribut

jangan sembarang melakukan ritual pada bagian utara perkampungan

Teks pada data (6), indeks arah berupa kata lau 'bagian utara'. Pada bagian utara perkampungan adat merupakan bagian yang tidak terpisahkan dengan bagian-bagian yang lainya sehingga perlu di lakukan ritual secara teliti. Hal tersebut dilakukan karena pada dasarnya masyarakat etnik Lio meyakini bahwa setiap tempat memiliki penghuninya yaitu setan/jin.

\section{8 laki gha ale tau mawe-mawe}

ketua adat disini buat pelan-pelan

'ketua adat melaksanakannya dengan baik'

\section{9 laki gha kengi do ngere wawi bani}

ketua adat disin gurau seperti babi marah

'ketua adat marah' 
10 nia ria rembe lalu da gha ... o gha graru da gha... muka besar rambat jantan disini yang disini san disini 'muka berseri-seri keriangan'

Teks pada data (7-9) di atas, Indeks ruang berupa kata gha 'di sini' merepresentasikan keadaan atau tempat berlangsungnya tarian gawi. Pada data 7 Kata di sini menunjukan tempat yang telah disiapkan untuk melangsungkan ritual serta tarian gawi. Teks pada data 8 kata $g h a$ ' $d i$ sini' menunjukkan posisi ketua adat yang berada berdekatan dengan sumber suara atau penyanyi. Penyanyi mengungkapkan bahwa saat ini ketua adat berang karena banyak peserta yang belum mengikuti tarian Gawi. Teks pada data (9) indeks gha 'di sini' menunjukan orang-orang saat itu sangat senang, terutama kaum pria, yang di metaforakan dengan nia rembe lalu 'muka ayam jantan'. Diketahui bahwa tarian Gawi merupakan tarian yang dilakukan sekelompok orang dengan membentuk lingkaran yang berlapis-lapis. Tangan-tangan orang yang melakukan tarian gawi saling bergenggaman satu sama lain sehingga para pemuda menggunakan kesempatan ini untuk bergenggaman tangan dengan para gadis. Ungkapa metaforik tersebut sesungguhnya hanya lelucon dari penyanyi karena melihat para peserta yang sangat menikmati dan bersemangat.

\subsubsection{Indeks Temporal}

Menurut Danesi, (2004: 43) indeks temporal menghubungkan benda-benda dari segi waktu, dengan penggunaan kata kata keterangan seperti sebelum, sesudah, sekarang, atau saat itu dalam bahasa Indonesia. Grafik garis waktu dapat digambarkan untuk melambangkan poinpoin waktu yang berhubungan yang terletak di kiri dan kana. Indeks temporal dalam analisis ini mengacu pada kata penghubung atau konjungsi yang berkaitan dengan suatu peritiwa atau kejadian, baik kejadian pada masa lampau, saat ini, maupun masa yang akan datang. Berikut ini ada beberapa contoh indeks temporal yang terdapat dalam lirik lagu Gawi "Ine Pare" karya Frans Tuku.

11 o... sai nala mulu o embu pera guru... a...аe...e...

o... sejak lama duluan yang leluhur tunjuk guru .......ae...e....

'leluhur telah mengajarkannya sejak dahulu'

12 joka walo ju sai nala mulu

tolak lagi penyakit dari dulu

'menolak penyakit yang telah berlalu'

Indeks temporal pada data 10 ditunjukkan dengan frasa sai nala mulu 'sejak dahulu'. Yang dalam konteks ini penyair mengungkapkan bahwa ritual yang dilaksanakan merupakan warisan leluhur sejak dahulu. Makna tersebut merepresentasikan bahwa semua kegiatan acara adat yang dilakukan merupakan ajaran dari leluhur sejak zaman dahulu dan mereka yang melaksanakan ritual tersebut saat ini merupakan orang-orang yang menjalankan perintah leluhur. Demikian pula dengan data nimor (11), frasa sai nala mulu 'sejak dahulu', yang merepresentasikan 
pelaksanaan ritual pengusiran roh-roh halus yang terus dilakukan sejak zaman dahulu hingga saat ini.

\subsubsection{Indeks Persona}

Danesi, (2004: 43) mengungkapkan bahwa indeks persona menghubungkan pihak-pihak yang mengambil bagian dalam sebuah situasi. Misalnya dengan penggunaan ganti orang seperti $a k u$, kau, ia, atau kata ganti tak-tertentu seperti yang itu dan yang lain. Dalam kontenteks teks lirik lagu Gawi "Ine Pare" karya Frans Tuku, penggunaan indeks persona banyak di temui dikarenakan beberapa faktor di antaranya, lawan tutur, situasi, usia lawan tutur, kedudukan seseorang dan lain sebagainya.

Berdasarkan hasil identifikasi data, hanya terdapat kata ganti pertama jamak yaitu kami dan kita, serta kata ganti orang kedua jamak kalian seperti dalam beberapa kutipan di bawah ini.

13 ole....ole...ole weta.... 3x... kita budu se sama-sama

ole... ole... ole saudari $3 \mathrm{x}$ kitaa hentak segera sama-sama

'mari-mari sudari kita hentak kaki bersama-sama

14 ma'eke sadhu madhu miu nuwa muri jemu

jangan cuek cuek kalian pemuda pemudi

jangan cuek saja kalian pemuda pemudi

\section{5 miu laki juju $n d u$...}

kalian ketua adat

'para ketua adat yang mengikutinya'

16 sama lelu kami sama koti daki lima rapa ndawi ola tuke sani

seperti benang kami gasing dengan tangan baku pegang alam topang pusat

'bersama-sama bergandengan tangan'

\section{7 miu paga ana ma'e gharu ramba leka ngawu ata re...}

kalian memelihara anak jangan mengambil barang orang le...

'carilah makanan yang halal untuk anak-anak'

Teks data 12 di atas, terdapat indeks persona yang di tunjukan dengan kata kita 'kita' yang merujuk pada semua yang hadir. Makna dari indeks persona ini adalah bentuk ajakan untuk melakukan tarian gawi kepada semua hadirin yang hadir. Indeks persona pada data 12 me representasi bahwa tarian ini merupakan tarian yang melibatkan banyak orang. Pada teks data (13) indeks persona ditunjukkan dengan kata miu 'kalian' yang merujuk pada pemuda-pemudi yang hadir dalam cara tersebut. Representasi makna indek persona pada data (13) menunjukan bahwa yang melakukan tarian Gawi tersebut bukan saja orang yang sudah tua melainkan semua galongan termasuk muda-mudi. Pada teks data (14), indeks persona ditunjukan dengan kata miu 'kalian' yang dalam konteks ini merujuk pada seluruh ketua adat yang hadir pada saat itu. Indeks persona pada data (14), merepresentasi ajakan agar seluruh anggota ketua adat juga terlibat atau melakukan tarian gawi bersama masyarakat. Pada data 15 indeks persona ditunjukkan dengan 
kata kami 'kami' yang merujuk pada seluruh hadirin yang hadir. Representasi makna indeks pada data (15) menggambarkan kebersamaan dengan saling berpegangan tangan yang menunjukkan bahwa kekuatan berada pada kebersamaan masyarakat. Jika semua masyarakat bersama-sama atau bersatu maka hidup akan lebih baik. Pada data 16 indek persona ditunjukan dengan kata miu 'kalian' yang merujuk pada pemuda-pemudi. Representasi makna indeks persona pada data 16 merupakan pesan kepada pemuda-pemudi yang telah tiba saatnya mencari pasangan agar kelak menapatkan yang keturunan harus besarkan anak secara baik dan benar, diberi makanan yang halal dan jangan mengambil hak orang lain.

\subsection{Simbol}

Danesi, (2010: 38-44) Simbol adalah tanda yang mewakili objeknya, melalui kesepakatan atau persetujuan dalam konteks spesifik. Makna - makna dalam suatu simbol dibangun melalui kesepakatan sosial atau melalui beberapa tradisi historis. Pendapat tersebut menyiratkan bahwa, Simbol merupakan bentuk bahasa baik berupa kata, frasa maupun kalimat. Bentuk bahasa atau simbol verbal tidak ada keterkaitan langsung dengan objek yang diacu melainkan kesepakatan mamsyrakat pengguna bahasa tertentu.

Berdasarkan hasil identifikasi tanda, simbol mendominasi teks lirik lagu gawi karya Frans Tuku. Berikut ini beberapa cuplikan tanda simbol yang terdapat dalam lirik laagu gawi karya Frans Tuku.

18 ele...le..le...ole Laki tau nggua nama bapu bewale..le... ele...le..le... ole ele...le..le...ole ketua tua adat buat ritual adat nama leluhur panjang ya le..le...

'Ketua adat melaksanakan ritual adat musim tanam untuk mengenang kembali leluhur'.

19 laki tau nggua kiwa iwa duna le......le...

ketua buat ritual adat tahun tidak kurang le......le...

'ketua adat melakukan ritual adat tiap tahunya ya...ya...'

\section{0 laki wenggo ulu eko}

ketua adat pindah ujung ekor

'ketua adat memidahkan ke ujung'

Tanda Simbol pertama pada lirik lagu Gawi karya Frans Tuku adalah laki/mosa laki "ketua adat" seperti terdapat pada data $(17,18,19)$. Secara leksikal mosalaki terdiri atas dua kata yaitu, mosa 'jantan' laki 'pemimpin'. Secara harfiah kedua kata ini mengnadung makna kepemimpinan. Mosalaki merupakan simbol pemimpin pada suatu wilayah adat. Mosalaki memiliki kedudukan dan status sosial lebih tinggi dalam kebudayaan etnik Lio. Mosalaki bertugas menjaga hak ulayat, menjalankan seremonial adat (nggua) dan menjaga anakalo faiwalu 'masyarakatnya' agar tetap rukun, damai dan sejahtera. Penyelenggaraan acara adat (nggua) adalah salah satu upaya ketua adat menjaga keberlangsungan hidup bagi masyarakatnya sehingga dimana acara tersebut merupakan warisan leluhur yang harus dijaga dan dilestarikan. 
Dalam kepercayaan etnik Lio, jika acara atau ritual adat penyambutan musim tanam nggua ini tidak dilaksanakan akan terjadi bencana.

\section{1 miu laki dari sama kemamera bari \\ kalian ketua adat berdiri kerja duduk baris \\ 'kalian ketua adat harus bekerja sama'}

Teks pada data 20, tanda simbol ditunjukan dengan kalimat Miu laki dari sama yang bermakna seruan kepada tetua adat yang ada di perkampungan tersebut. Simbol pada data (20) bermakna bahwa di setiap perkampungan adat terdapat beberapa ketua adat. yaitu, setiap perkampungan adat masyarakat etnik Lio terdapat beberapa ketua adat. Ketua adat utama memegang peranan paling besar, dalam hal melaksanakan ritual ataupun membahas suatu permasalahan. Ketua adat utama melakukan musyawara mufakat bersama anggota mosalaki lain untuk mengambil keputusan. Sama halnya dengan acara-acara seremonial adat, ketua adat akan menggundang seluruh anggotanya untuk rapat bermufakat bersama. Beberapa hal tersebut menunjukan bahwa ketua adat masyarakat etnik Lio tidak bekerja dengan sendiri melainkan melibatkan anggotanya dalam mengambil suatu keputusan atau kebijakan.

\section{2 fai ana kalo ma'e gena buru...}

istri anak yatim jangan kena penyakit

'masyarakat terhindar dari penyakit'

\section{3 miu ana kalo dheka ngere lako}

mereka anak yatim gonggong seperti anjing

'masyarakat banyak'

\section{4 miu faiwalu keri ngere manu, ola jere paru lela ghawa lau}

kalian perempuan janda memanggil ayam akan bergerak lari terbang kesana 'rakyat biasa seperti ayam'

Pada data (21-23) terdapat tanda simbol berupa frasa anakalo faiwatu 'rakyat jelata' . Anakalo faiwalu secar leksikal terdiri atas empat kata yaitu; ana 'anak', kalo 'yatim', fai 'perempuan' dan walu 'janda'. Secara harfiah, keempat kata ini mengandung makna rakyat jelata. Simbol pada data (21-23) merepresentasi rakyat yang tidak memiliki harta benda ataupun warisan. Anak yatim ataupun perempuan janda mendapatkan jatah tanah dari ketua adat. Tanah yang diberikan ketua adat, dijadikan tempat bercocok tanam.

25 ju paru reo mai duna rewo a...a.ae.....

penyakit lari sembarang datang kurang sembarang a...a..ae.....

'penyakit sedang sedang mengintai'

Teks pada data (24), indeks ditunjukkan dengan frasa Ju paru reo 'penyakit sedang sedang mengintai'. Simbol pada data (24) mepresentasi keyakinan atau kepercayaan masyrakat etnik Lio 
bahwa penyakit/hama itu ada, seketika bisa menyerang baik pada tanaman maupun masyarakat. Oleh karena itu, harus dilakukan ritual adat (nggua) sebelum melakukan bercocok tanam.

26 joka towa-dowa telo mori mona // joka dowa-dowa telo mori mona tolak semua-semua telur buaya lepas // tolak semua-semua telur buaya lepasle 'memohon agar semua masyarakat hidup dengan baik'

Teks pada data (25) di atas simbol ditunjukkan dengan frasa telo mori mona "telur buaya yang busuk". Telur buaya yang busuk merupakan metafora untuk mengungkapkan marabahaya yang dapat merusak kehidupan baik manusia maupun hasil pertanian. Represesentasi Makna simbol pada data (25) yakni kekwatirn ketua adat akan pendapatn dan kesehatan seluruh masyarakat adatnya.

27 imu molo dowa ma'e wi'a wogha le.... teman baik sudah jangan pisah lagi le... 'tetaplah bersama jangan berpisah lagi

28 Miu paga ana ma'e gharu ramba leka ngawu ata re... kalian memelihara anak jangan mengambil barang orang le... 'peliharalah anak masing-masing dengan jujur'

Teks data 26 simbol Imu molo dowa ma'e wi'a wogha le "sudah bersama jangan berpisah lagi" ungkapan tersebut diarahkan kepada muda-mudi kelak kalau telah mendapatkan pasangan hidup jangan berpisah lagi. Teka data (26) merepresentasikan realitas kehidupan rumah tangga baru sering terjadi perpisahan oleh karena factor sosial dan ekonomi

. Teks data 27, simbol ditunjukkan dengan Miu paga ana ma'e gharu ramba leka ngawu ata re "kalian membesarkan anak jangan dengan hasil curian" ungkapan tersebut bermakna pesan kepada muda-mudi yang kelak akan menikah untuk tidak berbuat curang dalam mencari nafkah. Data symbol (27) merepresentasi keresahan pengarang/ penyanyi terhadapan muda-mudi yang menikah di usia mudah.

29 lau leka nggoka eo joga goma disana pada semut yang masuk tidak bisa 'Pada lubang yang tidak bisa dilalui semut'

30 lia kalembate meko mawe-mawe lubang lebah gerak pelan-pelan 'di lubang lebah bergeraklah pelan-pelan'.

Teks pada data (28) simbol berupa kalimat lau leka nggoka eo joga gomall lau leka nua ndere eo mele mare "Pada lubang yang tidak bisa dilalui semut". Kalimat ini menggunakan metafora yang bermakna 'walaupun tidak bisa tapi dipaksakan'. Simbol pada data (28) 
merepresentasikan dinamika sosial budaya yang terjadi khususnya pada muda-mudi. Realitas menunjukan kebanyakan pernikahan di usia dini yang disebabkan oleh pergaulan bebas.

Teks pada data (29), simbol ditunjukkan dengan kalimat lia kalembate meko mawe-mawe 'dilubang lebah bergerak pelan-pelan'. Kalimat tersebut menggunakan metafora yang bermakna sesorang yang mengetahui perbuatanya tersebut salah tapi dipaksakan untuk melakukanya. Pada teks data (29) merepresentasikan beberapa kejadian sosial diantaranya pernikahan sedarah, pernikahan atara bapak dan anak maupun sebaliknya ibu dengan anaknya yang pada dasarnya tidak sesuai dengan norma adat maupun agama.

\section{1 ghea tubu kanga leka lodo nda}

di sana potongan batu pada tempat datar

"potongan batu yang berada di arena"

Teks pada data (30), frasa tubu kanga leka lodo nda 'potongan batu' merupakan tanda dimana tali pusat manusia dikuburkan. Tali pusat manusia merupakan simbol yang bermakna permulaan kehidupan. Representasi makna simbol data (30) yaitu batu yang berada di tengahtengah arena berbentuk lonjong sebagai pusat permulaan kehidupan maka, ditempat itulah dilakukan ritual menaruh sesajian serta melakukan tarian Gawi sebagai ungkapan rasa syukur kepada sang pemilik kehidupan yaitu dua nggae no dua bapu ata mata 'tuhan yang maha kuasa dan leluhur.

\section{Kesimpulan dan Saran}

Berdasarkan hasil analisis data ditemukan tanda berupa ikon, seperti kata Gawi "Tandak" dan mosalaki 'ketua adat'. Indeks ruang berupa penunjukkan arah diantaranya, ghele 'timur', ghale 'atas', ghawa 'barat', lau 'utara', dan gha 'di sini'. Indeks temporal terdapat satu frasa yakni, saimulu nala 'sejak dahulu kala'. Indeks persona diantaranya; kita 'kita' dan miu 'kalian'. Simbol yang terdapat pada lirik lagu Gawi "Ine Pare" karya Frans Tuku diantaranya; mosalaki 'ketua adat', miu laki dari sama 'kalian ketua adat', anakalo faiwalu 'rakyat jelata', ju paru reo 'penyakit mengintai', telo mori mona 'telur buaya rusak', imu molo dowa ma'e wi'a wola 'hidup sudah baik jangan terpisah lagi', miu paga ana ma'e gharu remba leka ngawu ata 'kalian membesarkan anak dengan makanan yang halal' (8) lau leka nggoka eo jiga goma 'disana biar semutpun tidak bisa masuk' (9) lia kalembate meko mawe-mawe 'gerak perlahan-lahan pada lubang tawon' (10) ghea tubu kanga ghea lodo nda 'disana tugu/batu pusat'.

Representasi makna ikon Gawi pada lirik lagu Gawi “ine pare’ karya Frans Tuku adalah momentum mempererat hubungan tali persaudaraan antara sesama dan ungkapan rasa syukur kepada sang pencipta dan leluhur. Representasi makna Ikon nggua pada lirik lagu Gawi "Ine Pare" karya Frans Tuku adalah; pesta adat penyambutan musim tanam yang diselenggarakan pada saat memasuki musim penghujan. Indeks ruang bermakna penunjukkan ruang atau arah tempat. Representasi makna indeks yaitu; berkaitan dengan tempat-tempat dilakukanya ritual adat nggua. Representasi makna indeks temporal; pelaksanaan ritual adat nggua yang dilakukan merupakan amanat leluhur yang harus di jaga dan dijalankan sehingga masyarakat terselamatkan 
dari mara bahaya atau bencana. Representasi makna indeks personal; orang-orang yang terlibat pada saat ritual maupun pada saat melakukan tarian Gawi. Representasi makna simbol pada lirik lagu Gawi "Ine Pare" karya Frans Tuku secara umum merepresentasikan realitas sosial-budaya masyarakat etnik Lio. Mosalaki memegang peranan penting dalam adat istiadat yang diwarisi leluhur diantaranya nasalah sosial-budaya, ekonomi dan lain sebagainya. Selain itu, makna simbol pada lirik lagu Gawi "Ine Pare" karya Frans Tuku merepresentasikan masalah-masalah sosial yang terjadi seperti perbuatan yang melanggar norma adat istiadat seperti kecurangan dalam mencari nafka, perkawinan dini serta perkawinan sedarah.

Lagu gawi bukan hanya sekedar musik yang mengiringi tarian Gawi 'tandak' lebih dari pada itu, lagu Gawi memberikan pesan dan makna luhur bagi para pendengar terutama masyrakat etnik Lio. Oleh karena itu, penulis menyarankan hal sebagai berikut; (1) bagi para pencipta lagu gawi agar terus berkaria dan meberikan inovasi-inovasi agar lagu tersebut semakin diminati terutama kaum mudah; (2) bagi masyarakat etnik Lio, Gawi merupakan warisan budaya etnik Lio yang harus jaga dan dilestarikan; (3) bagi peneliti; penelitian ini terbatas pada tanda, makna, dan representasi makna pada teks lirik lagu Gawi "Ine Pare" karya Frans Tuku. Oleh karena itu, sangat diharapkan jika peneliti lain mengkajinya dengan menggunakan perspektif atau teori lainya.

\section{Daftar Referensi}

Budiman, Kris. 2003. Semiotika Visual. Yogyakarta: Penerbit Buku Baik.

Chaer, Abdul. 2007. Linguistik Umum. Jakarta: Rineka Cipta.

Denesi, Marcel. 2004. Pesan, Tanda dan Makna: Buku Teks Dasar Mengenai Semiotika dan Teori. Yogyakarta: Jalasutra

Eriyanto. 2001. Analisis Wacana: Pengantar Analisis Teks Media. Yogyakarta: LKiS.

Hoed, Beny. 2011. Semiotik dan Dinamika Sosial Budaya. Depok- Jakarta, Komunitas Bambu.

Littlejohn, Stephen W dan Karen A. Foss. 2009.Teori Komunikasi : Theories of Human Communication. Jakarta: Salemba Humanika

Nana Syaodih Sukmadinata. (2011). Metode Penelitian Pendidikan. Bandung: PT Remaja Rosdakarya.

Palmer, Gary B. 1996. Toward a Theory of Cultural Linguistiks, 1st Edition. Texas: The University of Texas Press.

Rima Ambarsari, Desy (2012) Analisis Semiotika Makna Kehidupan Dalam Lirik Lagu Sujiwo Tejo "Pada Suatu Ketika". Thesis, UPN "VETERAN" Yogyakarta.

Sukmadinata, N.S. 2011. Metode Penelitian Pendidikan. Bandung: Remaja Rosadakarya

Sutopo. 2006. Metodologi Penelitian Kualitatif. Surakarta: UNS

Sugiyono, 2009. Metode Penelitian Kuantitatif, Kualitatif dan R\&D, Bandung : Alfabeta. 